\title{
Vulnerable Plaque in Patients with Acute Coronary Syndrome: Identification, Importance, and Management
}

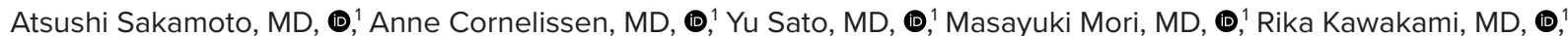

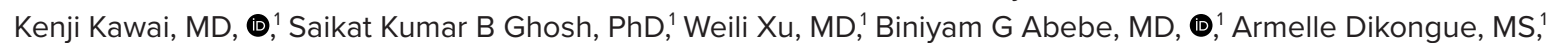 \\ Frank D Kolodgie, PhD, (®, Renu Virmani, MD, ®, and Aloke V Finn, MD, (1,2
}

1. CVPath Institute, Gaithersburg, MD; 2. University of Maryland, School of Medicine, Baltimore, MD

\begin{abstract}
$\mathrm{MI}$ is a leading cause of morbidity and mortality worldwide. Coronary artery thrombosis is the final pathologic feature of the most cases of acute MI primarily caused by atherosclerotic coronary artery disease. The concept of vulnerable plaque has evolved over the years but originated from early pioneering work unveiling the crucial role of plaque rupture and subsequent coronary thrombosis as the dominant cause of MI. Along with systemic cardiovascular risk factors, developments of intravascular and non-invasive imaging modalities have allowed us to identify coronary plaques thought to be at high risk for rupture. However, morphological features alone may only be one of many factors which promote plaque progression. The current vulnerable-plaque-oriented approaches to accomplish personalized risk assessment and treatment have significant room for improvement. In this review, the authors discuss recent advances in the understanding of vulnerable plaque and its management strategy from pathology and clinical perspectives.
\end{abstract}

\section{Keywords}

Vulnerable plaque, acute coronary syndrome, plaque rupture, thin-cap fibroatheroma

\begin{abstract}
Disclosure: AC receives research grants from University Hospital RWTH Aachen. RV has received honoraria from Abbott Vascular, Biosensors, Boston Scientific, Celonova, Cook Medical, Cordis, CSI, Lutonix Bard, Medtronic, OrbusNeich Medical, CeloNova, SINOMED, ReCore, Terumo, WL Gore, and Spectranetics, and is a consultant for Abbott Vascular, Boston Scientific, Celonova, Cook Medical, Cordis, CSI, Edwards Lifesciences, Lutonix Bard, Medtronic, OrbusNeich Medical, ReCore, Sinomededical Technology, Spectranetics, Surmodics, Terumo Corporation, WL Gore, and Xeltis. AVF has received honoraria from Abbott Vascular, Biosensors, Boston Scientific, Celonova, Cook Medical, CSI, Lutonix Bard, Sinomed, and Terumo, and is a consultant for Amgen, Abbott Vascular, Boston Scientific, Celonova, Cook Medical, Lutonix Bard, and Sinomed. CVPath Institute has received institutional research support from R01 HL141425 Leducq Foundation Grant, 480 Biomedical, 4C Medical, 4Tech, Abbott, Accumedical, Amgen, Biosensors, Boston Scientific, Cardiac Implants, Celonova, Claret Medical, Concept Medical, Cook, CSI, DuNing, Inc, Edwards LifeSciences, Emboline, Endotronix, Envision Scientific, Lutonix/Bard, Gateway, Lifetech, Limflo, MedAlliance, Medtronic, Mercator, Merill, Microport Medical, Microvention, Mitraalign, Mitra assist, NAMSA, Nanova, Neovasc, NIPRO, Novogate, Occulotech, OrbusNeich Medical, Phenox, Profusa, Protembis, Qool, Recor, Senseonics, Shockwave, SINOMED, Spectranetics, Surmodics, Symic, Vesper, WL Gore, and Xeltis. All other authors have no conflicts of interest to declare.

Funding: This study was sponsored by CVPath Institute.

Received: July 7, 2021 Accepted: October 7, 2021 Citation: US Cardiology Review 2022;16:e01. DOI: https://doi.org/10.15420/usc.2021.22

Correspondence: Aloke V Finn, CVPath Institute, 19 Firstfield Rd, Gaithersburg, MD 20878. E: afinn@cvpath.org
\end{abstract}

Open Access: This work is open access under the CC-BY-NC 4.0 License which allows users to copy, redistribute and make derivative works for non-commercial purposes, provided the original work is cited correctly.

MI was once considered a major health concern in industrialized nations, but is now seen routinely worldwide including in developing countries, which bear the greatest burden of cardiovascular disease. Coronary artery thrombosis is the final pathologic finding in most cases of $\mathrm{Ml}$ and is mainly caused by atherosclerotic coronary artery disease (CAD). ${ }^{2}$ Our understanding of 'vulnerable plaques', defined as rupture-prone (or event-prone) plaques, has advanced dramatically in the last two decades, along with its recognition and subsequent treatment. This has been the result of advancements in basic and clinical investigations along with the development of imaging techniques and treatment technologies. However, at the same time, the results of vulnerable-plaque-oriented approaches to accomplish personalized risk assessment, stratification and treatment have room for significant improvement. In this review, we discuss the recent advancements in our understanding of vulnerable plaque and its management strategies from pathology to clinical management.

\section{Plaque Phenotype as a Cause of Coronary Thrombosis}

Prior autopsy studies have recognized three distinct morphologic entities leading to coronary thrombosis: plaque rupture (PR), plaque erosion (PE), and calcified nodules (CN; Figures $1 A-1 C){ }^{3}$ Our autopsy series of more than 800 people who died suddenly because of coronary artery thrombosis revealed that $55-60 \%$ of cases had underlying PR, 30-35\% of the etiology was PE, and in $2-7 \%$ it was because of $\mathrm{CN}^{2}$ A worldwide review of 22 autopsy studies, including 1,847 cases of hospital-based acute $\mathrm{Ml}$ and sudden coronary death, also showed that $73 \%$ of fatal coronary thrombi originated from PR and $27 \%$ from PE. ${ }^{4}$

\section{Plaque Rupture}

PR refers to an advanced atheromatous lesion consisting of necrotic core with an overlying ruptured thin fibrous cap. 'Rupture' represents a structural defect in the fibrous cap that separates the highly thrombotic 
Figure 1: Pathology and Intra-coronary Imaging (OCT) of Human Coronary Artery Morphologies Associated With ACS

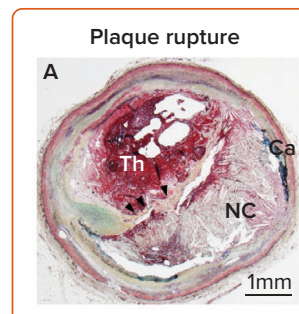

Thin-cap fibroatheroma

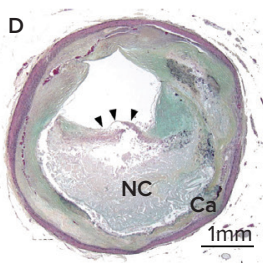

Plaque rupture

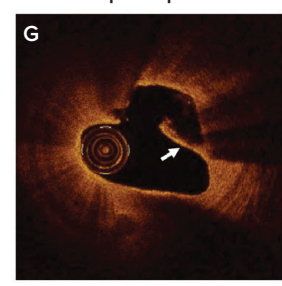

Thin-cap fibroatheroma
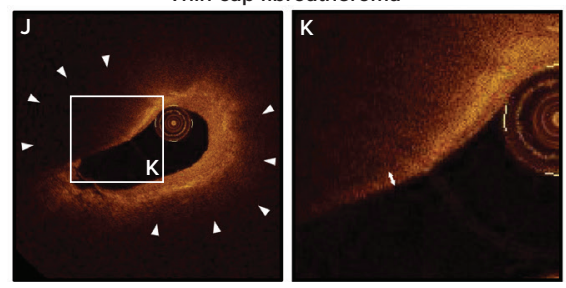

Pathologic (A-F) and OCT-based classification (G-K) of human coronary artery associated with ACS. A: plaque rupture; B: plaque erosion with underlying pathologic intimal thickening; C: calcified nodule; D: thin-cap fibroatheroma (black arrowhead shows thin fibrous cap); E: intra-plaque hemorrhage; F: nodular calcification; G: OCT-plaque rupture (white arrow shows disrupted thin fibrous cap); H; OCT-erosion (white arrow shows white thrombus); I: OCT-calcified nodule (white arrow shows overlying superficial calcification with red thrombus); J-K: thin-cap fibroatheroma. J shows low-power image. $K$ is high-power magnification of the rectangular area in J. The white arrow head in J shows low backscattering, signal-poor region with diffuse border, suggesting large necrotic core. The double-head white arrow in K shows thin fibrous cap. $A C S=$ acute coronary syndrome; $C a=$ calcification; $I P H=$ intra-plaque hemorrhage; $L P=$ lipid pool; $N C=$ necrotic core; $O C T=$ optical coherence tomography; $T$ h = thrombus. Source: Panels G, H, J and K: Otsuka et al. 2014. ${ }^{12}$ Adapted with permission from Springer Nature. Panel I: Jia et al. 2013. ${ }^{13}$ Adapted with permission from Elsevier.

necrotic core contents from the bloodstream. ${ }^{5}$ It has been considered that the site of rupture is usually located at its mechanically weakest point, often near the shoulder regions. ${ }^{6}$ However, this is not always the case, as we have observed a comparable number of ruptures at the mid portion of the fibrous cap, especially in individuals who are dying during exertion. Therefore, it is reasonable that multiple processes can be involved in the mechanisms of fibrous cap rupture, e.g. fibrous cap degradation by matrix metalloproteinases released from inflammatory cells, great wall shear stress, and macrophage and smooth-muscle-cell apoptosis in the cap, as previously reported. ${ }^{8-10}$ The exposure to the blood of the lipid-rich necrotic core containing a large amount of prothrombotic tissue factor activates the coagulation cascade, resulting in the occlusion of the coronary artery by thrombus formation and subsequent MI." As will be discussed below, the vulnerable plaque paradigm is largely based on the mechanisms and morphologic characteristics thought to promote PR.

\section{Plaque Erosion}

The second common cause of intracoronary thrombosis is PE, which is defined as intracoronary thrombosis without evidence of fibrous cap rupture but that may include a necrotic core. ${ }^{3}$ As pathologic studies have revealed, the denudated endothelial layer is usually observed in the culprit site of PE. ${ }^{3}$ Exposure of underlying proteoglycans and collagen could be the nidus for thrombus formation. Generally, the underlying plaque phenotype is fibroatheroma with a thick fibrous cap or pathologic intimal thickening. Recent innovation of in vivo intra-coronary imaging modalities, such as optical coherence tomography (OCT), has allowed us to understand the underlying etiology of acute coronary syndromes (ACS) in the clinical setting. ${ }^{12}$ OCT studies of clinically determined ACS cases suggested the prevalence of PE is $27-31 \%{ }^{13,14}$ According to pathology and OCT studies, individuals of younger age (i.e. $<50$ years), female sex, and smokers are more likely to develop PE compared to PR..$^{13,15,16}$ Moreover, traditional risk factors (e.g. diabetes, hypertension, hyperlipidemia, and chronic kidney disease) are less common in PE than PR. 17,18 Local disturbed blood flow, toll-like receptor-2 activation in endothelial cells, endothelial apoptosis, concentrated extracellular matrix (e.g. hyaluronan and versican) in the subendothelial intimal layer, granulocyte rich inflammatory response, and neutrophil extracellular trap formation are considered to be underlying mechanisms of PE. ${ }^{19}$ However, the precursor lesion to thrombotic $P E$ is still unclear, and the exact series of events that predispose to $P E$ are unknown. Therefore, at present, the concept of vulnerable plaque pertaining to PE has not been developed and requires further investigation.

\section{Calcified Nodule}

$\mathrm{CN}$ is a third common mechanism of intracoronary thrombosis, with a prevalence of $3.3 \%$ in our autopsy case series who died suddenly due to acute coronary thrombosis. ${ }^{3}$ OCT-based clinical studies suggest the prevalence of $\mathrm{CN}$ in ACS is $2-8 \%{ }^{13,20}$ Pathologically, $\mathrm{CN}$ is defined as a disrupted luminal surface by nodules of dense calcium with overlying thrombus and little or no underlying necrotic core in arteries that are highly calcified, tortuous, and often have large sheets of calcification. Pathologic definitions of 'eruptive calcified nodule' (Figure $1 C$ ) and 'nodular calcification' (Figure 1F) need to be differentiated; the latter occurs within the plaque and does not involve disruption of the fibrous cap or contact with the lumen, but it is often associated with medial wall disruption with or without extension into the adventitia. The mechanism of fibrous cap disruption in $\mathrm{CN}$ causing overlying thrombosis is thought to be the fragmentation of necrotic core calcification by mechanical means. Areas of $\mathrm{CN}$ are often sandwiched between proximal and distal hard sheet calcification (most frequent in the mid-right coronary artery or left anterior descending artery-sites of maximal torsion). ${ }^{3,21}$ These sites of nodular calcification serve as sites of hinge motion and repeated trauma is thought to encourage the creation of nodules of calcium that can protrude into the lumen causing thrombosis. However, in order to define the precursor lesion to $\mathrm{CN}$, further clinical investigations with better resolution imaging modalities need to be conducted.

\section{What is the Concept of Vulnerable Plaque? \\ Thin-cap Fibroatheroma as a Precursor Lesion of Plaque Rupture}

In the 1980s, James Muller coined the term 'vulnerable plaques' as precursor lesions from which Mls frequently developed. ${ }^{22}$ The morphological criteria for the definition of thin-cap fibroatheroma (TCFA) 
or vulnerable plaque originated from the concept that lesions that precede PR should have similar features (Figure 1D). Generally, ruptured plaques have large necrotic cores with ruptured thin fibrous caps accompanied by inflammatory cell infiltration including macrophages and - to a lesser extent - T lymphocytes, along with scant or a complete lack of smooth muscle cells. Our pathologic observation in cases of coronary PR revealed the thickness of the fibrous cap close to the rupture site was $23 \pm 19 \mu \mathrm{m}$, with $95 \%$ of caps measuring $<65 \mu \mathrm{m}$. ${ }^{23}$ Lesions with intact (non-ruptured) fibrous caps of $<65 \mu \mathrm{m}$ are also detected in non-culprit sites/vessels in patients dying of acute PR and are designated vulnerable plaques or TCFAs. In the year 2000, TCFA as the vulnerable plaque phenotype was first highlighted in a modified American Heart Association consensus described by Virmani et al. ${ }^{3}$ Subsequently, TCFA as the precursor lesion of PR became widely recognized; therefore, the original definition of vulnerable plaque is exclusively applicable to the PR paradigm.

Similar to PR, most TCFAs locate in the proximal segment of major coronary arteries. ${ }^{24}$ The pathologic features of TCFA are different from ruptured plaques in terms of smaller necrotic cores, less macrophage infiltration in the fibrous cap, and less calcification. ${ }^{25,26}$ Additionally, 70\% of cases of sudden coronary death by acute PR commonly show evidence of TCFAs in non-culprit lesion or vessels. ${ }^{27}$ The frequency of TCFA was much smaller (around 30\%) in people who died with flow-limiting severe coronary stenosis with stable fibrocalcific plaques. These findings imply that the presence of TCFA and rupture are not directly correlated (i.e. some TCFA may proceed to rupture while others do not)..$^{26}$ In addition, previous basic studies have revealed that inflammation, matrix metalloproteinases activity, and necrotic core expansion are all enhanced when TCFA is transforming into unstable plaques. ${ }^{8,28-32}$ However, precise triggers critical to the phenotypic transformation of TCFA plaques are still unclear.

\section{Intra-Plaque Hemorrhage: Another Vulnerable Plaque Phenotype}

Intra-plaque hemorrhage (IPH; Figure $1 E$ ) is considered one of the factors contributing to plaque destabilization and sudden increase in plaque volume. ${ }^{32,33}$ In 1987, Glagov reported that atherosclerotic coronary arteries undergo a progressive enlargement (i.e. positive remodeling) that allows preservation of the lumen area up to a point. ${ }^{34}$ Stenosis of the lumen only occurs once a plaque develops beyond $40 \%$ cross-sectional area (CSA) narrowing. ${ }^{34}$ Repeated subclinical PR and healing with luminal thrombus, as well as IPH (without luminal thrombus), are two major critical contributors for progressive plaque expansion until vessel occlusion and symptom onset. ${ }^{35}$ According to a large series of human plaques from cases of sudden coronary death, signs of previous IPH were frequently found in high-risk plaques prone to rupture compared to early lesion and stable plaques. Previously, our group showed the accumulation of erythrocyte membranes that contain a large amount of free cholesterol at the site of IPH contributes to the necrotic core expansion and further plaque vulnerability. ${ }^{36}$ Moreover, IPH is the essential trigger for macrophage phenotypic conversion into alternative subtypes distinct from lipid-laden foamy macrophages. ${ }^{37} \mathrm{IPH}$ results in erythrocyte lysis through oxidative stress with release of free hemoglobin. ${ }^{38}$ Free hemoglobin immediately forms complexes with plasma haptoglobin, and macrophages internalize hemoglobin-haptoglobin complexes via the CD163 scavenger receptor for effective clearance. ${ }^{39,40}$ Recently, we reported that the mechanisms of CD163-positive alternative macrophages provoke micro angiogenesis and microvascular permeability by releasing vascular endothelial growth factor responding to hemoglobin- haptoglobin stimuli. ${ }^{41}$ Thereby, small amounts of intimal angiogenesis and bleeding could be exacerbated by the inflammatory response, initiating a vicious cycle whereby bleeding begets more bleeding. Collectively, both components, including cholesterol-rich erythrocyte membrane and released hemoglobin at the site of $\mathrm{IPH}$, may synergistically accelerate plaque vulnerability leading to further adverse cardiovascular complications.

\section{Calcification in the Plaque: The Contradictory Role on Plaque Vulnerability}

Calcification is one of the common features of advanced atherosclerotic lesions, which develops and progresses with plaque type and luminal narrowing. ${ }^{42}$ A robust amount of clinical data has confirmed that the degree of coronary artery calcification is directly related to adverse cardiovascular outcomes in all populations, and it is a more reliable marker for future events than using risk equations based upon traditional risk factors (e.g. Framingham risk index). ${ }^{43}$ However, whether the coronary calcified plaques directly cause cardiac events or are just a reliable surrogate marker for the presence of CAD burden on a population-based level remains uncertain. Indeed, whether the presence of coronary calcification predicts plaque instability or stability is a crucial question for daily practice. One cannot treat coronary artery calcification as an all-ornone variable.

The type of calcification, location, volume, as well as density may all affect clinical risk and outcomes in distinctive ways. ${ }^{44} \mathrm{~A}$ study conducted detailed pathologic analysis of calcification, which included 510 coronary segments (17 cases) from acute Ml cases, as well as 450 segments (15 cases) from age-matched controls who died of non-cardiac causes ${ }^{45}$ In patient-based analysis, calcification was more abundant in cases of acute $\mathrm{Ml}$ versus controls. However, in lesion-based analysis, an inverse correlation was observed between the extension of calcification and cap inflammation. Multivariate regression analysis confirmed that the calcification was not correlated with the presence of unstable plaques. ${ }^{45}$ Recent imagingbased human studies suggested that spotty calcification predicts plaque vulnerability in patients presenting with ACS, while large and heavy calcification correlates with overall plaque burden in the coronary tree. ${ }^{46}$ Spotty calcification with positive vessel remodeling and low attenuation, detected by coronary CT angiography (CCTA), was more frequent in patients with ACS or likely to develop ACS in the short term. ${ }^{47}$ This imagingbased spotty calcification ( $<3 \mathrm{~mm}$ diameter) is comparable with pathological fragmented calcification, which is frequently found in the outer rim of necrotic core (this should not be confused with microcalcification mentioned below). ${ }^{48}$ According to these pathologic observations, progressive calcification of human plaque occurs from the outer rim of the necrotic core into the surrounding collagenous matrix while the central core is preserved at this stage. ${ }^{48}$ When the calcification progresses into the central necrotic core, the calcification turns into sheets, a typical feature of stable calcified plaque. Therefore, in pathology, coronary calcium burden is greater in stable fibrocalcific plaques than unstable plaques including PR and TCFA and exhibit an opposite correlation with necrotic core area. Coronary calcium scoring might be helpful to detect the general risk of adverse coronary events in a population, i.e. suggesting the presence of coronary atherosclerotic plaque. However, it is not useful specifically to prospectively identify a culprit lesion of a future ACS.

Regarding direct correlation between calcification and plaque vulnerability, Vengrenyuk et al. proposed the role of microcalcification in the cap as one of the contributors of fibrous cap rupture behaving as local 
Figure 2: Characteristics of Invasive and Non-invasive Coronary Imaging Modalities to Detect High-risk Vulnerable Plaques

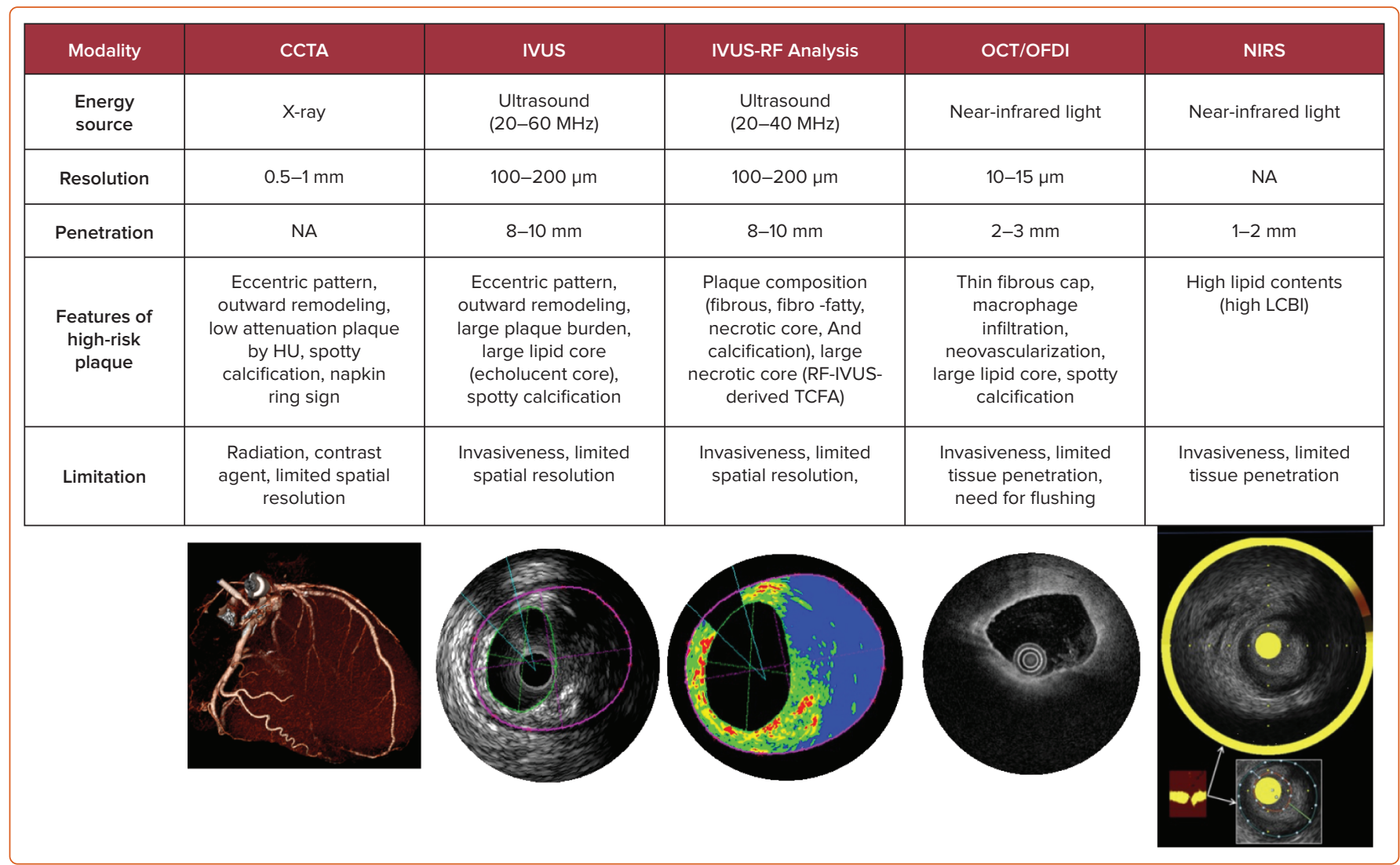

CCTA = coronary CT angiography; HU = Hounsfield unit; IVUS = intravascular ultrasound; RF = radiofrequency; OCT = optical coherence tomography; OFDI = optical frequency domain imaging; NIRS = near-infrared spectroscopy; NA = not applicable; TCFA = thin-cap fibroatheroma; $L C B I=$ lipid-core burden index. Source: Madder et al..$^{83}$ Adapted with permission from Elsevier.

tissues stress concentrators. ${ }^{49,50}$ However, pathologically defined microcalcification (i.e. 0.5-15 $\mu \mathrm{m}$ diameter) requires extremely high spatial resolution to visualize and cannot be evaluated by current in-vivo clinical imaging. ${ }^{49-52}$ The detection of microcalcification in the fibrous cap could potentially be one of the predictors for vulnerable plaque. However, innovations in coronary imaging modalities are necessary to make them useful for this purpose.

\section{Identification of Vulnerable Plaque by Imaging Modalities}

A comprehensive risk stratification with high accuracy for determining an individual's cardiovascular risk is desired. The scoring tools based on traditional risk factors such as age, sex, smoking, blood pressure, diabetes, and cholesterol levels (e.g. Framingham risk score, the Systematic Coronary Risk Evaluation, and Atherosclerotic Cardiovascular Disease risk estimator) could successfully stratify cardiovascular risk in whole populations. ${ }^{43,53,54}$ However, their effectiveness is limited by variations in lifetime risk level of patients and/or discrepancies between different algorithms arising from varying risk factors evaluated. Thus, in general practice, the use of currently developed risk stratification algorithms is low because of their oversimplification and concerns with over prescribing of medications. ${ }^{55}$ Moreover, most cardiovascular events occur in patients classified as low or intermediate risk by traditional risk factors. ${ }^{56}$

Therefore, more reliable atherosclerotic lesion-based stratifications by coronary imaging modalities are still considered worthy of study by cardiovascular clinicians and researchers. The characteristics of imaging modalities for high-risk coronary plaque detection and the summary of large clinical trials examining the effectiveness for these modalities are shown in Figure 2 and Table 1. ${ }^{57-69}$

\section{Coronary CT Angiography}

Substantial evidence suggests that coronary plaque burden is associated with the likelihood of future cardiovascular events. Coronary artery calcium score as assessed by CCTA has been shown to be predictive of coronary events in different ethnic populations independently of standard risk factors or scores. ${ }^{70}$ Further, an assessment of plaque vulnerability by CCTA is also thought to improve the diagnostic accuracy for patients with CAD. CCTA can provide reliable assessment in terms of the presence, size, and thickness of necrotic core, by grading tissue in Hounsfield units $(\mathrm{HU}) .^{71}$ Currently accepted high-risk plaque characteristics by CCTA include positive remodeling (remodeling index $\geq 1.1$ ), low-attenuation (a focal central area of plaque with an attenuation density of $<30 \mathrm{HU}$ ), spotty calcification ( $<3 \mathrm{~mm}$ in maximum diameter), and napkin-ring sign (i.e. a central area of low-attenuation plaque with a peripheral rim of high attenuation). These high-risk features are robust markers of ruptureprone lesions supported by evidence gained from multiple clinical studies. For instance, the recently reported SCOT-HEART trial, which included 1,769 cases with 5 years of follow-up, demonstrated that patients with adverse plaque characteristics (i.e. positive remodeling or low attenuation plaque) have a greater risk of coronary death or non-fatal MI. ${ }^{58}$ Moreover, a large-scale clinical CCTA study (3,158 patients) also indicated that the combination of high-risk plaque characteristics, significant stenosis, and plaque progression by serial examination allows for better prognostic values for future ACS events. ${ }^{59}$ 


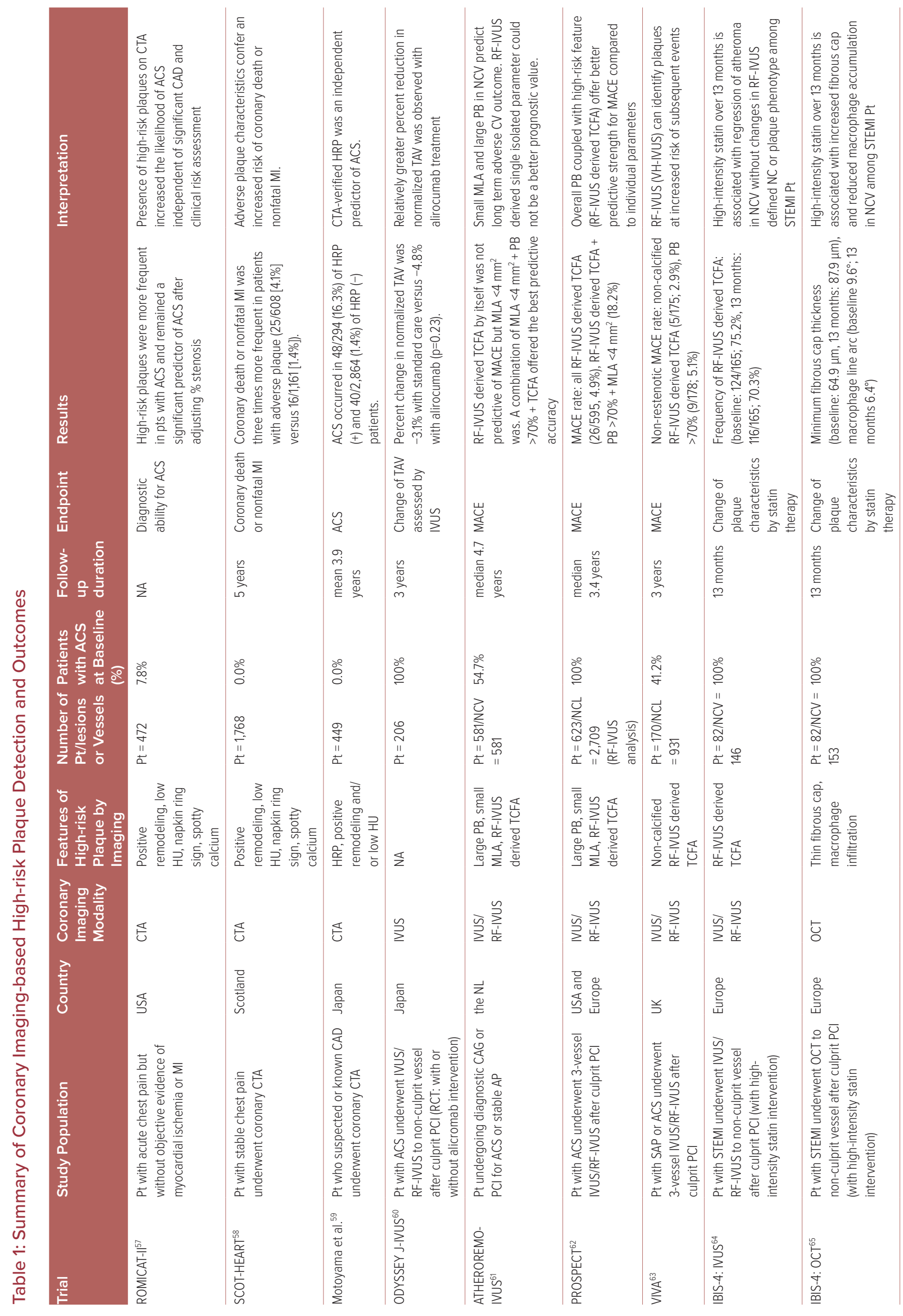




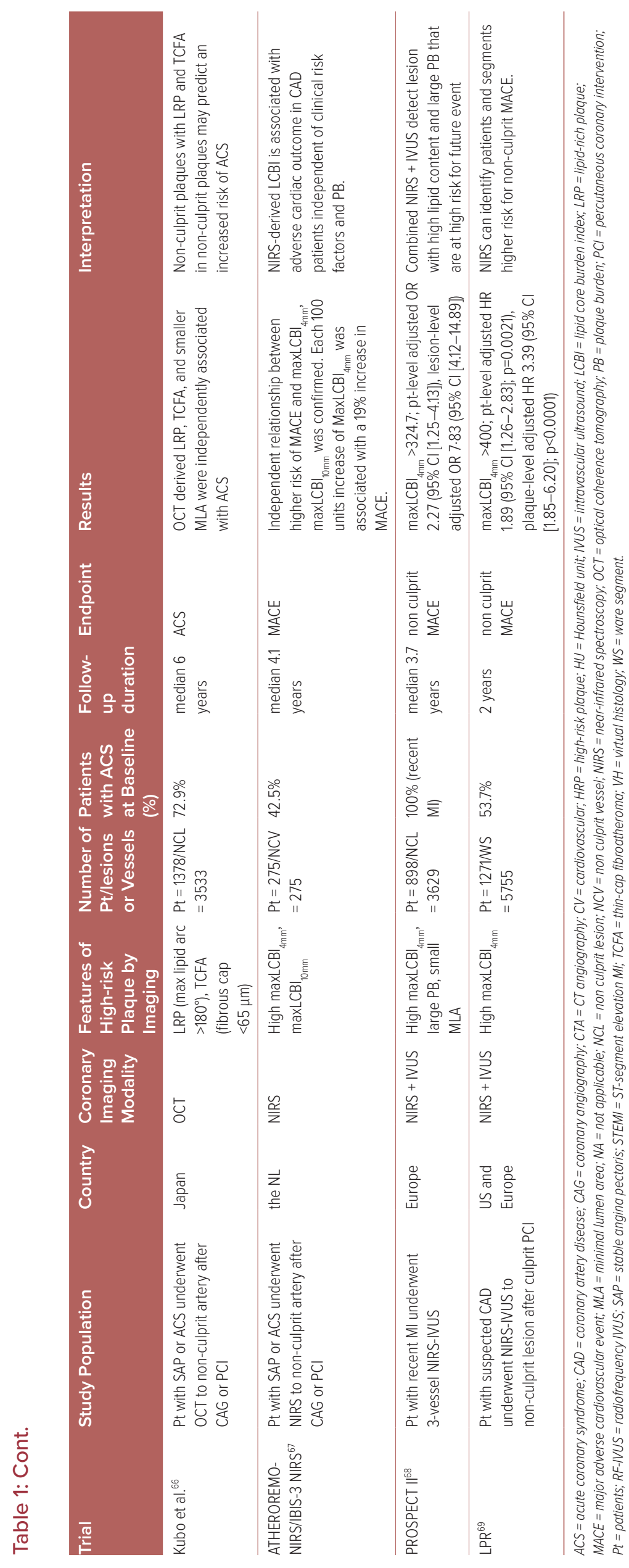




\section{Intravascular Ultrasound}

A number of pathologic studies and clinical papers have proposed the idea of precursor lesion to PR that could be located and treated before it causes coronary events. Catheter-based invasive imaging techniques, including intravascular ultrasound (IVUS), can identify some features of 'vulnerable plaques' in atherosclerotic lesions in daily practice, although it cannot visualize exact thinness of the fibrous cap and other more specific details (resolution of IVUS $>100 \mu \mathrm{m}$ ). In grayscale IVUS images, coronary plaques can be classified as soft, intermediate, calcified, or mixed according to their echo signals. Additionally, assessment of plaque burden (formula: plaque plus media CSA/external elastic membrane CSA), vessel remodeling index (formula: lesion external elastic membrane CSA/ reference external elastic membrane CSA), atheroma eccentricity (formula: [maximum plaque + media thickness - minimum plaque + media thickness]/maximum plaque + media thickness), as well as plaque characterization by reflecting echo signal amplitude, frequency, and power (e.g. integrated backscatter IVUS and virtual histology IVUS.) can provide additional information about potential vulnerable plaque, with the idea that once identified we would be able to treat them before an event can occur. ${ }^{62,72,73}$ Accordingly, larger plaque burden, eccentric pattern, outward remodeling (remodeling index $>1.0$ ), spotty calcification, signal attenuation without dense calcium, presence of an echolucent zone, and plaque composition of necrotic core determined by radiofrequency analysis have been reported to be vulnerable plaque characteristics. ${ }^{74}$ However, in general, the results of clinical studies have not clearly supported the theory of IVUS-defined TCFAs as the lesion causing clinical events. The PROSPECT trial was a prospective study of 697 ACS patients who underwent three-vessel coronary angiography and gray-scale and radiofrequency IVUS. ${ }^{62}$ From 595 identified IVUS-defined TCFAs, only 26 sites had a coronary event at a median follow-up of 3.4 years. When combined with other criteria, such as a plaque burden of $>70 \%$ and a minimum lumen area of $<4 \mathrm{~mm}^{2}$, the HR increased to 11.05 for any lesion having these criteria, yet $88.2 \%$ of patients harboring these plaques did not go on to have an event during the study. Another clinical study using virtual histology IVUS also revealed similar results, although the number of patients and follow-up duration were lower. ${ }^{63}$

\section{Optical Coherence Tomography}

Optical coherence tomography (OCT) is another major coronary artery invasive imaging modality using near-infrared light and has 10 times greater resolution compared with IVUS (resolution $>10 \mu \mathrm{m}$ ). Therefore, fibrous cap thickness can be measured by OCT, and this technology has emerged as the best discriminator of plaque type in autopsy studies. ${ }^{75,76,77}$ To verify the findings of pathologic autopsy study regarding fibrous cap thickness and other features in coronary plaques, an OCT- and IVUSbased in-vivo clinical study was conducted. ${ }^{23,78}$ The specific morphological characteristics of ruptured culprit plaque responsible for acute events, ruptured non-culprit plaques (without lumen occlusion), and non-ruptured TCFA were compared in patients with ACS. ${ }^{78}$ In total 126 plaques from 82 cases were analyzed, and fibrous cap thickness was thinner in ruptured plaques (both culprit [43 $\pm 11 \mu \mathrm{m}]$ and non-culprit [41 $\pm 10 \mu \mathrm{m}]$ lesions) than in TCFA (56 $\pm 9 \mu \mathrm{m}, p<0.001$ and $p<0.001$, respectively).

Another OCT-based clinical study involving 643 plaques from 255 patients showed that TCFA were highly prevalent in various stages of coronary atherosclerotic disease suggesting their dynamic nature. ${ }^{79}$ Compared to mildly stenotic TCFAs, severely stenotic TCFAs showed greater plaque burden as well as more vulnerable plaque features. This suggests severely stenotic TCFAs may be more likely to lead to rupture and thrombosis in the near future. Recently, Kubo et al. demonstrated a prospective OCT study, including 3,533 non-culprit plaques from 1,378 patients. ${ }^{66}$ Seventy-two ACS arose from initial non-culprit plaques within 6 years of follow-up. A larger maximum lipid arc, thinner minimum fibrous cap thickness, and smaller minimum lumen area were independent risks for subsequent ACS at the lesion level. ${ }^{66}$ On the other hand, regarding other vulnerable plaque characteristics, such as IPH and microcalcification in the fibrous cap, the performance of OCT remains uncertain (i.e. the former is because of the complex findings during healing of hemorrhage in the necrotic core, and the latter is because of the lower end of the spectrum [microcalcification $<5 \mu$ m diameter]). In addition, discriminating calcified areas from lipid core in OCT is difficult as both appear as signalpoor regions. ${ }^{80}$

\section{Near-infrared Spectroscopy}

Near-infrared spectroscopy (NIRS) is another clinically available intracoronary imaging modality using characteristic emission spectra produced by plaque contents following interaction with photons. NIRS can be used to identify lipid core plaque (LCP) as validated in several pre-clinical and clinical studies. ${ }^{81-83}$ The calculated data by intra-coronary NIRS system provides a two-dimensional map of the vessel (chemogram), i.e. the $x$ - and $y$-axis represent pullback position and circumferential position in degrees $\left(0-360^{\circ}\right)$, respectively, with a color scale from red to yellow indicating probability for the LCP presence. From the chemogram, a summary metric of the probability of LCP presence in at a 2-mm interval during pullback can be computed and displayed in a color map (block chemogram). ${ }^{84}$ Lipid core burden index (LCBI) is a quantitative summary metric of the LCP presence in the entire scanned segment, which is the fraction of valid pixel in the chemogram that exceeds an LCP probability of 0.6 , multiplied by 1,000 . For instance, $\operatorname{maxLCBI}_{4 \mathrm{~mm}}$ indicates the maximum value of the $\mathrm{LCBI}$ for any of the $4 \mathrm{~mm}$ segments in the interrogated region. ${ }^{84}$ This method is able to quantify the lipid content of plaque, especially in cases of positive remodeling with large lipid-rich necrotic core. ${ }^{85}$

A recent large-scale clinical trial using NIRS, the LPR study, revealed the usefulness of NIRS-based vulnerable plaque and patient risk stratification. ${ }^{69}$ A total of 1,563 patients with CAD underwent NIRS-IVUS assessment in two or more non-culprit arteries, and patient- and plaque-level events were enrolled. To examine the association between maximum $4 \mathrm{~mm} \mathrm{LCBI}$ $\left(\operatorname{maxLCBI}_{4 \mathrm{~mm}}\right)$ and non-culprit major adverse cardiovascular events, patients with large versus small lipid-rich plaque (maxLCBI $_{4 \mathrm{~mm}} \geq 250$ versus maxLCBI $_{4 \mathrm{~mm}}<250$, respectively) were followed for up for 2 years. The adjusted patient-level analysis found an $18 \%$ higher risk of experiencing a non-culprit event within 2 years for each 100 unit increase in LCBI 4 mm segment. More recently the prospective multicenter trial PROSPECT II also examined the usefulness of combined coronary plaque assessment with NIRS + IVUS in 3,629 non-culprit lesions of 898 patients with recent MI. ${ }^{68}$ Adverse events within 4 years occurred in 112 patients (13.2\%), with 66 events $(8.0 \%)$ that originated from non-culprit lesions. Highly lipid-rich lesions assessed by maxLCBI ${ }_{4 \mathrm{~mm}}$, large plaque burden, as well as minimum lumen area were independent predictors of non-culprit lesion related MACEs. Although these data suggest plaque assessment by NIRS + IVUS can predict overall risk of events, analysis on an individual plaque basis was not presented. Therefore, on a patient- and plaque-specific basis, the technology could not discriminate the future risk of events in the near term for a specific plaque.

\section{What is the Significance of Vulnerable \\ Plaque Detection by Imaging Modalities?}

The fact that even PR events do not always cause acute MI or sudden coronary death and can happen without clinical symptoms complicates the 
Table 2. Factors and Conditions Associated with Increased Risk for Acute Coronary Events

\begin{tabular}{|c|c|c|c|c|c|}
\hline $\begin{array}{l}\text { Coronary Plaque } \\
\text { Characteristics }\end{array}$ & $\begin{array}{l}\text { Coronary Blood } \\
\text { Flow Dynamics }\end{array}$ & $\begin{array}{l}\text { Intrinsic Hemostasis } \\
\text { Factors }\end{array}$ & $\begin{array}{l}\text { Metabolic and } \\
\text { Inflammatory Conditions }\end{array}$ & $\begin{array}{l}\text { Neurohormonal } \\
\text { Imbalance }\end{array}$ & $\begin{array}{l}\text { Environmental } \\
\text { Factors and Drugs }\end{array}$ \\
\hline Plaque burden & Blood viscosity & Platelet function/volume & Diabetes & Stress & Smoking \\
\hline Lumen encroachment & Shear stress & Circadian variation & Obesity & Catecholamine surges & Pollution \\
\hline Lesion location & $\begin{array}{l}\text { Reduced blood flow/low } \\
\text { cardiac output }\end{array}$ & Factor V Leiden deficiency & Dyslipidemia & Depression & Climate \\
\hline Plaque composition & Vascular tone and reactivity & Von Willebrand factor deficiency & Connective tissue diseases & Exertion & Legal drugs \\
\hline Plaque biology & Arterial hypertension & Anti-phospholipid syndrome & Infections & Autonomic dysfunction & Illegal drugs \\
\hline $\begin{array}{l}\text { Plaque configuration and } \\
\text { remodeling }\end{array}$ & & & Renal disease & Endocrine imbalance & Diet \\
\hline Endothelial dysfunction & & & & & Sedentary lifestyle \\
\hline
\end{tabular}

Source: Arbab-Zadeh et al. ${ }^{94}$ Reproduced with permission from Wolters Kluwer Health.

quest to identify vulnerable plaque by imaging modalities in order to prevent clinical events. ${ }^{86,87}$ Arbab-Zadeh et al. reviewed 11 clinical and pathological studies involving 1,371 patients and identified subclinical PR was detected in the non-culprit lesion in $11.5 \%$ of patients with stable CAD or healthy controls, as well as $21.5 \%$ of patients who presented with ACS. ${ }^{87}$

Prior pathological evidence by Mann et al. advanced the theory that repeated silent PRs are one of the critical triggers of phasic rather than linear progression of luminal narrowing in diseased coronary arteries which may involve subclinical thrombus formation and healing. ${ }^{88}$ Also, a histopathology study from our group involving 142 cases who died of sudden coronary death revealed frequent observation of multiple healed PR sites with layering in the lesion with acute and healed PR. ${ }^{35}$ Moreover, in patients dying without acute thrombus, healed PR sites were identified in $80 \%$ of cases, and cumulative healed PRs at the same location clearly related to increased percentage stenosis. Combined with the evidence from IVUS-based studies that $75 \%$ of TCFAs convert into thick-capped fibroatheromas within a 12 month follow-up period, silent PR and healing are not uncommon in vivo. ${ }^{89}$ Together, this evidence suggests that even if the location of vulnerable plaque was detected precisely, many of them would not cause clinically important symptomatic events. Furthermore, multiple sub-clinical ruptured plaques as well as non-ruptured TCFA have been detected in addition to culprit lesions in patients with ACS, suggesting a systemic condition leading plaque vulnerability throughout the coronary tree..$^{90}$ The concept of the 'vulnerable patient' as a contributor to near-term events in subjects harboring multiple vulnerable plaques needs more attention. ${ }^{91,92}$

\section{Factors Associated With Acute Coronary Event: Plaque Development and Coagulation Status}

The vast majority of sites identified by imaging as vulnerable plaque (TCFA) do not cause symptomatic arterial thrombotic occlusion. The above-mentioned PROSPECT trial showed that only 4.4\% (26/595) of nonculprit TCFA lesions detected by Virtual Histology-IVUS (VH-IVUS) in 313 patients turned in clinically detectable thrombotic events during 3 years follow up. ${ }^{62}$ Indeed, large number of plaque rupture or erosion event can happen silently (without leading symptomatic coronary events) as shown in pathology and clinical studies. ${ }^{2,93}$ These silent thrombotic events mainly result in plaque volume progression by intramural thrombus organization rather than life threatening acute coronary occlusion and MI. Therefore, although the release of pro-thrombotic necrotic core components (e.g. tissue factor) to blood stream after fibrous cap disruption in PR or the exposure of pro-thrombotic subendothelial tissue matrix caused by endothelial disruption in PE can be an initial trigger of thrombotic formation. Multiple other factors may also contribute to subsequent thrombus enlargement and final luminal occlusion. Factors and conditions associated with increased acute coronary event risk may be further categorized into being related to plaque characteristics, coronary flow dynamics, intrinsic hemostatic/fibrinolytic dysfunction, neurohormonal dysregulation, and environmental factors and triggers as shown by ArbabZadeh et al. (Table 2) ${ }^{94}$ Therefore, even though the detection of vulnerable plaque is a quite important, for comprehensive understanding of acute coronary event (to recognize 'vulnerable patient'), identification of factors associated with plaque development/progression, with local/systemic blood procoagulant status, or with combination of them need to be considered. In this regard, cardiovascular physicians need to appreciate these nuances - many of which remain incompletely understood.

\section{Management and Treatment of Coronary Vulnerable Plaque}

Lipid-lowering Treatment

A number of clinical trials revealed that the reduction of LDL cholesterol with statins is associated with improvements in fatal cardiovascular events. ${ }^{95}$ According to the recently available clinical guidelines, lipidlowering using statins is a standard treatment for the primary and secondary prevention of cardiovascular disease caused by atherosclerosis. ${ }^{96,97}$ Furthermore, statin therapy is recommended in both ACS and prior to percutaneous coronary intervention (PCI), and this has originated from its pleiotropic effect on several cellular pathways regarding anti-inflammation and subsequent anti-thrombosis. ${ }^{98} \mathrm{~A}$ regression of coronary plaque burden by statin therapy was confirmed by observation with IVUS in a pooled analysis of eight clinical trials including 4,477 patients with high-risk plaques. ${ }^{99}$ The long-term effect of statin on coronary plaque was also confirmed in recent PARADIGM study. ${ }^{100}$ In this prospective, multinational trial over 2 years of follow-up, statin treatment was associated with slower progression of overall coronary atherosclerosis, a reduction of high-risk plaque characteristics, and increased plaque calcification. ${ }^{100}$ A reduction of plaque burden and an increase in fibrous cap thickness of coronary fibroatheroma was also confirmed by several OCT-based clinical studies. ${ }^{101}$ When comparing lowand high-dose statin treatment, high-dose treatment was associated with fewer vulnerable plaque features including lipid volume and fibrous cap thickness confirmed by serial OCT observation. ${ }^{102}$

In addition to statins, proprotein convertase subtilisin/kexin type 9 (PCSK9) inhibitors have recently emerged as another intensive lipid-lowering agent. ${ }^{103}$ Large scale randomized controlled trials confirmed the significant effect of PCSK9 inhibitors on LDL-cholesterol levels as well as 
cardiovascular event reductions in patients with a background of statin therapy. ${ }^{104,105}$ The updated European lipid-lowering guideline recommends adding a PCSK9 inhibitor early after the ACS event in patients whose LDLcholesterol levels have not reached goal despite maximum tolerated statin and ezetimibe treatment. ${ }^{97}$ The US guidelines consider patients with ACS within 12 months as a very high-risk population. In patients in this category whose LDL-C level is $>1.8 \mathrm{mmol} / /$ on maximally tolerated statin and ezetimibe, adding a PCSK9 inhibitor in this setting is reasonable. ${ }^{106} \mathrm{~A}$ study of the GLAGOV trial, which investigated 968 statin-treated CAD patients who underwent serial IVUS imaging before and after (i.e. 76 weeks) adding placebo or evolocumab treatment, revealed greater reduction of atheroma volume in evolocumab group. ${ }^{107}$ However, serial plaque compositions assessed by virtual histology IVUS were similar between evolocumab and placebo groups. ${ }^{107}$ An ongoing multicenter, double-blind, placebo-controlled trial, PACMAN-AMI, will determine the effect of alirocumab on top of high-intensity statin therapy on high-risk coronary plaque characteristics by serial assessment with intra-coronary multimodalities including IVUS, NIRS, and OCT. ${ }^{108}$

\section{Anti-inflammatory Treatment}

More than two decades ago, the role of inflammation in atherosclerosis was raised as a potentially important target. ${ }^{109}$ Ridker et al. demonstrated apparently healthy individuals with elevated levels of high-sensitive C-reactive protein (hsCRP) to be at high vascular risk (Ml and stroke) irrespective of lipid levels. ${ }^{109}$ Recently, the inflammatory character of atherosclerosis has come into the forefront with the results of several clinical trials.

The effect of canakinumab, a therapeutic monoclonal antibody targeting interleukin (IL)-1ß was tested in a large scale randomized, double-blind trial, CANTOS. ${ }^{110}$ A total of 10,061 patients with previous $\mathrm{Ml}$ history with elevated hsCRP were randomly allocated to canakinumab and placebo and followed-up for 3.7 years. The anti-inflammatory therapy achieved a $15 \%$ relative reduction in risk for recurrent $\mathrm{MI}$, stroke, or cardiac death. Individuals who responded to canakinumab therapy by accomplishing a greater than median reduction in hsCRP had a $26 \%$ reduction in the primary end point and a decrease in all-cause mortality. Because IL-1 $\beta$ participates in host defenses, canakinumab treatment was also associated with a higher incidence of fatal infection than placebo. Thus, the data did not completely support the use of anti-inflammatory medicines as a method to decrease plaque vulnerability, and the Food and Drug Administration did not support labeling for canakinumab as a targeted therapy for reduction of cardiovascular events.

Another anti-inflammatory agent, methotrexate, has also been tested for efficacy in cardiovascular risk prevention in a large scale, randomized, double-blind trial, and the result was recently reported."11 However, lowdose methotrexate did not reduce levels of IL-1 $1 \beta$, IL-6, or CRP and did not result in fewer cardiovascular events than the placebo.

Colchicine is an alkaloid derivative that has been traditionally used for treating gout as well as several other rheumatic diseases. ${ }^{112}$ Growing evidence suggests that colchicine's anti-inflammatory mechanisms, such as NLRP2 inflammasome inhibition, can be a treatment option for atherosclerotic disease. The effect of colchicine treatment in patients with stable CAD on top of statin and antiplatelet therapy was tested in two randomized clinical trials: LoDoCo and LoDoCo-2.113,14 The latter trial had a much larger population of 5,522 patients with stable CAD on statin and antiplatelet therapy who were allocated to colchicine versus placebo. Those who received colchicine had a $31 \%$ risk reduction in primary outcomes, including cardiovascular mortality, myocardial ischemia, ischemia-driven revascularization, and stroke compared with the placebo $(p<0.05) .{ }^{14}$ As opposed to canakinumab in the CANTOS trial, colchicine used in this study was not associated with an increased rate of hospitalization for infection. Moreover, colchicine's effect on secondary cardiovascular prevention was evaluated in the large scale COLCOT trial. ${ }^{115}$ In this study, 4,745 patients who had suffered a recent Ml were randomly assigned to two groups: low dose colchicine or placebo. The colchicine group had a significant risk reduction (23\%) in the primary composite end point, i.e. cardiovascular death, cardiac arrest, $\mathrm{Ml}$, stroke, or urgent coronary revascularization. Considering the inflammatory characteristics of ruptureprone vulnerable plaques, anti-inflammatory treatment might decrease the risk of rupture, but their routine use in this setting likely requires more data.

\section{Invasive Treatment}

As shown in the ISCHEMIA trial, our current understanding of the effectiveness of a $\mathrm{PCl}$ strategy added to guideline-directed medical therapy in patients with stable CAD is questionable, with likely no beneficial effect on cardiovascular outcomes compared to medical therapy alone. ${ }^{116}$ On the other hand, a recently reported meta-analysis analyzed 46 trials, including 37,757 patients, and revealed a beneficial effect of PCl in unstable patient scenarios including: post-MI patients who did not receive immediate revascularization; patients who underwent primary PCl for ST-elevation MI but with residual coronary lesions; and patients with non-ST-elevation MI. ${ }^{17}$ Overall, in these unstable scenarios, $\mathrm{PCl}$ reduced all cause of death ( $\mathrm{RR} \mathrm{0.84;} \mathrm{95 \%} \mathrm{Cl}$ [0.75-0.93]; $\mathrm{p}=0.02$ ), cardiac death (RR 0.69; 95\% Cl [0.53-0.90]; $p=0.007$ ) and MI (RR 0.74; $95 \% \mathrm{Cl}[0.62-0.90] ; \mathrm{p}=0.002$ ). Patients undergoing coronary angiography often present with multi-vessel disease, and the finding of vulnerable plaques is common under observation with in-vivo imaging modalities, especially in unstable scenarios. However, to date, there is no evidence that prophylactic revascularization of vulnerable plaques is beneficial, and the significance of imaging techniques in the assessment of vulnerable plaques still needs more evidence to be routinely considered as necessary. The CANARY trial tested the correlation between lipid rich plaque as detected by NIRS and periprocedural MI presumably because of distal embolization. ${ }^{118}$ Eighty-five patients were enrolled at nine US sites. NIRS-IVUS were performed at baseline, and lesions with a $\operatorname{maxLCBI}_{4 \mathrm{~mm}}>600$ were randomly allocated to $\mathrm{PCl}$ with or without distal protection filter. Periprocedural MI developed in 21 patients (24.7\%) and the maxLCBI ${ }_{4 \mathrm{~mm}}$ was significantly higher in patients with versus without MI $(p<0.05)$. Although the beneficial effect of distal protection was not confirmed in 31 randomized lesions with $\operatorname{maxLCBI}_{4 \mathrm{~mm}}>600$ probably because of the lack of study power, the attempt to perform tailor-made $\mathrm{PCl}$ treatment with plaque characterization by contemporary coronary imaging needs further evaluation.

As mentioned above, current OCT imaging allows us to identify underlying plaque morphology in ACS. Compared with PR, the culprit lesion of PE typically has larger lumen, preserved vascular structure, and platelet-rich thrombus. ${ }^{13,15,119}$ Because drug-eluting stent implantation has the intrinsic disadvantages (e.g. the development of neoatherosclerosis, limiting normal vasomotion, and preclusion of bypass surgery due to metallic caging ${ }^{120,121)}$ conservative management with antithrombotic therapy (particularly antiplatelet therapy) without stenting can be a management option for ACS caused by PE. Several small clinical trials have shown the feasibility of this treatment strategy in short- and long-term outcomes. ${ }^{122,123}$ Large-scale randomized trials are needed to replicate these pilot study results and to further confirm long-term outcomes of this new treatment option in patients with ACS caused by PE. 
Figure 3: Concept of the 'Vulnerable Patient'

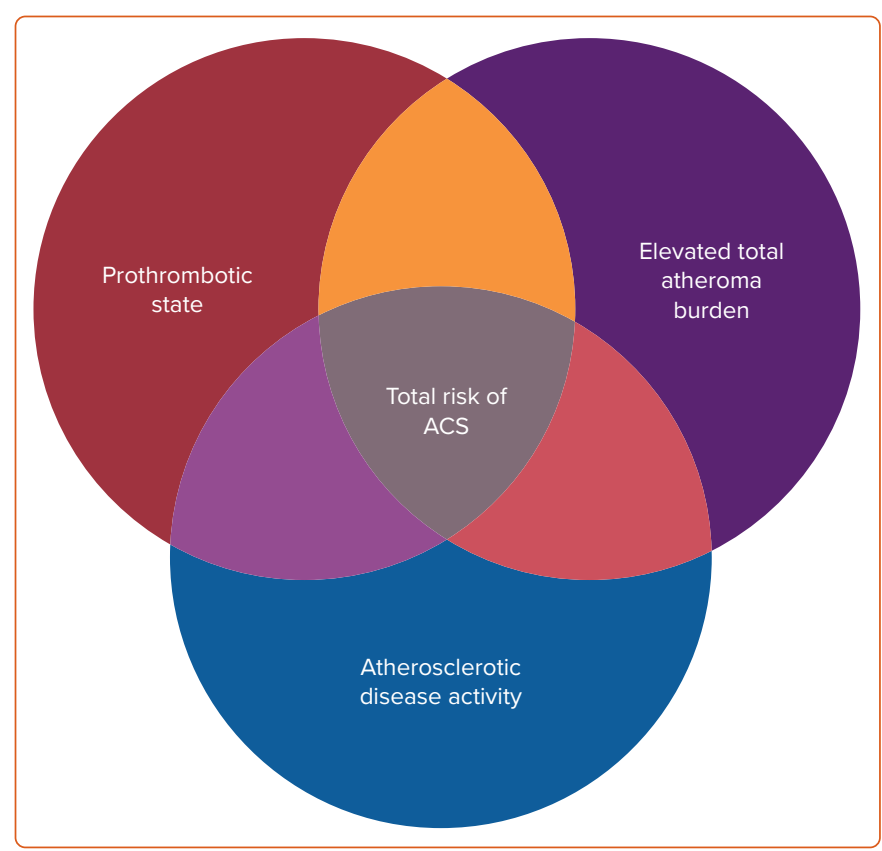

The illustration demonstrates the concept of vulnerable patients. A conglomerate of findings such as a prothrombotic state, elevated total atheroma burden and an overall systemic measure of atherosclerotic disease activity (for example inflammatory biomarkers) would constitute the vulnerable patient. ACS = acute coronary syndrome.

\section{Conclusion}

The vulnerable plaque concept originating from human pathology studies has led to a remarkable advancement in our understanding of pathogenesis and treatment for atherosclerosis. We know, to date, that comprehensive risk assessment needs to be performed to identify patients at risk for adverse cardiovascular events (Figure 3). Developments of invasive and non-invasive coronary imaging techniques are allowing for the detailed detection of rupture-prone vulnerable plaque characteristics. In combination with cardiovascular risk factors, plaque imaging might provide a more accurate picture of an individual's risk.

The diagnostic value of currently available intra-coronary imaging (e.g. IVUS, OCT, and NIRS) is extraordinary as many interventional cardiologists have already recognized. However, the use of intra-coronary imaging in daily practice is still low, especially in western countries. ${ }^{124}$ Its high cost, the prolongation of procedure time, and risk of complications are all potential reasons for the low adoption.124 As mentioned, a number of clinical studies have demonstrated the usefulness of current intracoronary imaging modalities not only to define plaque characterization but also to facilitate the optimal stenting process. Also, regarding economic impact, the favorable incremental cost-effectiveness of IVUSguided $\mathrm{PCl}$ versus angiography-guided $\mathrm{PCl}$ has been reported in several studies. ${ }^{125,126}$ Therefore, more use of intra-coronary imaging in daily clinical $\mathrm{PCl}$ procedures should be encouraged to achieve better clinical outcomes. Reimbursement issues as well as complexity in its interpretation (sometime requiring significant expertise) remain as additional barrier to its widespread adoption.

According to the results of large-scale clinical trials, the effectiveness of invasive PCl strategies in stable CAD patients is quite limited. Unstable patient populations who might harbor more vulnerable plaques need to be stratified, and more intensive medical therapeutic approaches need to be considered. As of now, imaging is not able to determine with high accuracy on a patient- or lesion-basis who is at high-risk in the near term for PR. More work needs to be done to understand other features that determine plaque vulnerability beyond those determined by morphology. In addition, the current approach of imaging-based vulnerable plaque detection is mainly focused on rupture prone lesions, which are represented as TCFA in pathology. Since the precursor lesion of PE and $\mathrm{CN}$ (more than $30 \%$ of the population in the case of ACS) has not been determined yet, further basic and clinical studies, including coronary imaging, need to be advanced for better risk stratification in patients with CAD. $\square$
1. Dai H, Much AA, Maor E, et al. Global, regional, and national burden of ischemic heart disease and its attributable risk factors, 1990-2017: results from the Global Burden of Disease Study 2017. Eur Heart J Qual Care Clin Outcomes 2021;7:574-82. https://doi.org/10.1093/ehjqcco/qcaa061; PMID: 32735316

2. Finn $\mathrm{AV}$, Nakano M, Narula J, et al. Concept of vulnerable/ unstable plaque. Arterioscler Thromb Vasc Biol 2010;30:1282 92. https://doi.org/10.1161/ATVBAHA.108.179739; PMID: 20554950

3. Virmani R, Kolodgie FD, Burke AP, et al. Lessons from sudden coronary death: a comprehensive morphological classification scheme for atherosclerotic lesions. Arterioscler Thromb Vasc Biol 2000;20:1262-75.10.1161/01.atv.20.5.1262. https://doi.org/10.1161/01.ATV.20.5.1262; PMID: 10807742.

4. Falk E, Nakano M, Bentzon JF, et al. Update on acute coronary syndromes: the pathologists' view. Eur Heart J 2013;34:719-28. https://doi.org/10.1093/eurheart//ehs411; PMID: 23242196.

5. Schaar JA, Muller JE, Falk E, et al. Terminology for high-risk and vulnerable coronary artery plaques. Report of a meeting on the vulnerable plaque, June 17 and 18, 2003, Santorini, Greece. Eur Heart J 2004;25:1077-82. https://doi. org/10.1016/j.ehj.2004.01.002; PMID: 15191780.

6. Pasterkamp G, Schoneveld AH, van der Wal AC, et al. Inflammation of the atherosclerotic cap and shoulder of the plaque is a common and locally observed feature in unruptured plaques of femoral and coronary arteries. Arterioscler Thromb Vasc Biol 1999;19:54-8. https://doi. org/10.1161/01.ATV191.54: PMID: 9888866

7. Burke AP, Farb A, Malcom GT, et al. Plaque rupture and sudden death related to exertion in men with coronary artery disease. JAMA 1999;281:921-6. https://doi.org/10.1001/ jama.281.10.921; PMID: 10078489.

8. Sukhova GK, Schönbeck U, Rabkin E, et al. Evidence for increased collagenolysis by interstitial collagenases-1 and -3 in vulnerable human atheromatous plaques. Circulation 1999;99:2503-9. https://doi.org/10.1161/01.CIR.99.19.2503; PMID: 10330380

9. Gijsen FJ, Wentzel JJ, Thury A, et al. Strain distribution over plaques in human coronary arteries relates to shear stress. Am J Physiol Heart Circ Physiol 2008;295:H160-14. https://doi org/101152/ajpheart.01081.2007: PMID: 18621851.

10. Kolodgie FD, Narula J, Burke AP, et al. Localization of apoptotic macrophages at the site of plaque rupture in sudden coronary death. Am J Pathol 2000;157:1259-68. https://doi.org/10.1016/S0002-9440(10)64641-X; PMID: 11021830.

11. Libby P. Mechanisms of acute coronary syndromes and their implications for therapy. N Engl J Med 2013;368:2004-13. https://doi.org/10.1056/NEJMra1216063; PMID: 23697515

12. Otsuka F, Joner M, Prati F, et al. Clinical classification of plaque morphology in coronary disease. Nat Rev Cardiol 2014;11:379-89. https://doi.org/10.1038/nrcardio.2014.62 PMID: 24776706.

13. Jia $\mathrm{H}$, Abtahian $\mathrm{F}$, Aguirre $\mathrm{AD}$, et al. In vivo diagnosis of plaque erosion and calcified nodule in patients with acute coronary syndrome by intravascular optical coherence tomography. J Am Coll Cardiol 2013;62:1748-58. https://doi. org/10.1016/j.jacc.2013.05.071; PMID: 23810884.

14. Higuma T, Soeda T, Abe N, et al. A combined optical coherence tomography and intravascular ultrasound study on plaque rupture, plaque erosion, and calcified nodule in patients with ST-segment elevation myocardial infarction: Incidence, morphologic characteristics, and outcomes afte percutaneous coronary intervention. JACC Cardiovasc Interv 2015;8:1166-76. https://doi.org/10.1016/j.jcin.2015.02.026; PMID: 26117464

15. Farb A, Burke AP, Tang AL, et al. Coronary plaque erosion without rupture into a lipid core. A frequent cause of coronary thrombosis in sudden coronary death. Circulation 1996;93:1354-63. https://doi.org/10.1161/01.CIR.93.7.1354;
PMID: 8641024.

16. Burke AP, Farb A, Malcom GT, et al. Effect of risk factors on the mechanism of acute thrombosis and sudden coronary death in women. Circulation 1998;97:2110-6. https://doi. org/10.1161/01.CIR.97.21.2110; PMID: 9626170.

17. Taylor AJ, Burke AP, O'Malley PG, et al. A comparison of the Framingham risk index, coronary artery calcification, and culprit plaque morphology in sudden cardiac death. Circulation 2000;101:1243-8. https://doi.org/10.1161/01. CIR.101.11.1243; PMID: 10725282.

18. Virmani R, Burke AP, Farb A. Plaque rupture and plaque erosion. Thromb Haemost 1999:82(Suppl 1):1-3 https://doi. org/10.1055/s-0037-1615543; PMID: 10695476.

19. Partida RA, Libby P, Crea F, et al. Plaque erosion: A new in vivo diagnosis and a potential major shift in the management of patients with acute coronary syndromes. Eur Heart J 2018;39:2070-6. https://doi.org/10.1093/ eurheartj/ehx786; PMID: 29329384.

20. Sugiyama T, Yamamoto E, Fracassi F, et al. Calcified plaques in patients with acute coronary syndromes. JACC CardiovasC Interv 2019;12:531-40. https://doi.org/10.1016/i. jcin.2018.12.013; PMID: 30898249

21. Torii S, Sato Y, Otsuka F, et al. Eruptive calcified nodules as a potential mechanism of acute coronary thrombosis and sudden death. J Am Coll Cardio/ 2021;77:1599-611. https://doi. org/10.1016/j.jacc.2021.02.016; PMID: 33795033.

22. Muller JE, Tofler GH, Stone PH. Circadian variation and triggers of onset of acute cardiovascular disease. Circulation 1989;79:733-43. https://doi.org/10.1161/01.CIR.79.4.733; PMID: 2647318.

23. Burke AP, Farb A, Malcom GT, et al. Coronary risk factors and plaque morphology in men with coronary disease who died suddenly. N Engl J Med 1997;336:1276-82. https://doi. org/10.1056/NEJM199705013361802; PMID: 9113930.

24. Wang JC, Normand SL, Mauri L, et al. Coronary artery spatial distribution of acute myocardial infarction occlusions. 
Circulation 2004;110:278-84. https://doi.org/10.1161/01. CIR.0000135468.67850.F4; PMID: 15249505.

25. Kolodgie FD, Burke AP, Farb A, et al. The thin-cap fibroatheroma: a type of vulnerable plaque: the major precursor lesion to acute coronary syndromes. Curr Opin Cardiol 2001;16:285-92. https://doi.org/10.1097/00001573200109000-00006: PMID: 11584167.

26. Kolodgie FD, Virmani R, Burke AP, et al. Pathologic assessment of the vulnerable human coronary plaque. Hea 2004;90:1385-91. https://doi.org/10.1136/hrt.2004.041798; PMID: 15547008.

27. Burke AP, Virmani R, Galis Z, et al. 34th Bethesda Conference: Task force \#2 what is the pathologic basis for new atherosclerosis imaging techniques? J Am Coll Cardiol 2003;41:1874-86. https://doi.org/10.1016/S07351097(03)00359-0: PMID: 12798554

28. Shah PK, Falk E, Badimon JJ, et al. Human monocytederived macrophages induce collagen breakdown in fibrous caps of atherosclerotic plaques. Potential role of matrixdegrading metalloproteinases and implications for plaque rupture. Circulation 1995:92:1565-9: PMID: 7664441.

29. Moreno PR, Falk E, Palacios IF, et al. Macrophage infiltration in acute coronary syndromes. Implications for plaque rupture. Circulation 1994;90:775-8. https://doi.org/10.1161/01. CIR.90.2.775; PMID: 8044947.

30. Galis ZS, Sukhova GK, Lark MW, et al. Increased expression of matrix metalloproteinases and matrix degrading activity in vulnerable regions of human atherosclerotic plaques. J Clin Invest 1994;94:2493-503. https://doi.org/10.1172/ JC1117619; PMID: 7989608.

31. Virmani R, Kolodgie FD, Burke AP, et al. Atherosclerotic plaque progression and vulnerability to rupture: angiogenesis as a source of intraplaque hemorrhage. Arterioscler Thromb Vasc Biol 2005;25:2054-61. https://doi. org/10.1161/01.ATV.0000178991.71605.18; PMID: 16037567.

32. Takaya N, Yuan C, Chu B, et al. Presence of intraplaque hemorrhage stimulates progression of carotid atherosclerotic plaques: a high-resolution magnetic resonance imaging study. Circulation 2005:111:2768-75. https://doi.org/10.1161/CIRCULATIONAHA.104.504167; PMID: 15911695.

33. Yahagi K, Kolodgie FD, Otsuka F, et al. Pathophysiology of native coronary, vein graft, and in-stent atherosclerosis. Nat Rev Cardio/ 2016:13:79-98. https://doi.org/10.1038/ nrcardio.2015.164; PMID: 26503410.

34. Glagov S, Weisenberg E, Zarins CK, et al. Compensatory enlargement of human atherosclerotic coronary arteries. N Engl J Med 1987;316:1371-5. https://doi.org/10.1056/ NEJM198705283162204; PMID: 3574413.

35. Burke AP, Kolodgie FD, Farb A, et al. Healed plaque ruptures and sudden coronary death: evidence that subclinical rupture has a role in plaque progression. Circulation 2001:103:934-40. https://doi.org/10.1161/01. CIR.103.7.934; PMID: 11181466

36. Kolodgie FD, Gold HK, Burke AP, et al. Intraplaque hemorrhage and progression of coronary atheroma. N Engl J Med 2003;349:2316-25. https://doi.org/10.1056/ NEJMoa035655; PMID: 14668457.

37. Jinnouchi H, Guo L, Sakamoto A, et al. Diversity of macrophage phenotypes and responses in atherosclerosis Cell Mol Life Sci 2020;77:1919-32. https://doi.org/10.1007/ s00018-019-03371-3; PMID: 31720740

38. Nagy E, Eaton JW, Jeney V, et al. Red cells, hemoglobin, heme, iron, and atherogenesis. Arterioscler Thromb Vasc Biol 2010;30:1347-53. https://doi.org/10.1161/ ATVBAHA 110 206433: PMID: 2037884

39. Kristiansen M, Graversen JH, Jacobsen C, et al. Identification of the haemoglobin scavenger receptor. Nature 2001;409:198-201. https://doi.org/10.1038/35051594; PMID: 11196644

40. Nielsen MJ, Møller HJ, Moestrup SK. Hemoglobin and heme scavenger receptors. Antioxid Redox Signal 2010;12:261-73. https://doi.org/10.1089/ars.2009.2792; PMID: 19659436

41. Guo L, Akahori H, Harari E, et al. CD163+ macrophages promote angiogenesis and vascular permeability accompanied by inflammation in atherosclerosis. J Clin Invest 2018;128:1106-24. https://doi.org/10.1172/JCI93025: PMID: 29457790.

42. Otsuka F, Sakakura K, Yahagi K, et al. Has our understanding of calcification in human coronary atherosclerosis progressed? Arterioscler Thromb Vasc Biol 2014;34:724-36. https://doi.org/10.1161/ATVBAHA.113.302642; PMID: 24558104.

43. Wilson PW, D'Agostino RB, Levy D, et al. Prediction of coronary heart disease using risk factor categories. Circulation 1998;97:1837-47. https://doi.org/10.1161/01. CIR.97.18.1837; PMID: 9603539

44. Shaw LJ, Narula J, Chandrashekhar Y. The never-ending story on coronary calcium: is it predictive, punitive, or protective? J Am Coll Cardio/ 2015;65:1283-5. https://doi. org/10.1016/j.jacc.2015.02.024; PMID: 25835439

45. Mauriello A, Servadei F, Zoccai GB, et al. Coronary calcification identifies the vulnerable patient rather than the vulnerable plaque. Atherosclerosis 2013;229:124-9. https:// doi.org/10.1016/j.atherosclerosis.2013.03.010; PMID: 23578355

46. van Velzen JE, de Graaf FR, de Graaf MA, et al. Comprehensive assessment of spotty calcifications on computed tomography angiography: comparison to plaque characteristics on intravascular ultrasound with radiofrequency backscatter analysis. J Nucl Cardiol 2011;18:893-903. https://doi.org/10.1007/s12350-011-9428-2; PMID: 21769702

47. Motoyama S, Kondo T, Sarai M, et al. Multislice computed tomographic characteristics of coronary lesions in acute coronary syndromes. J Am Coll Cardiol 2007:50:319-26. https://doi.org/10.1016/j.jacc.2007.03.044; PMID: 17659199.

48. Mori H, Torii S, Kutyna M, et al. Coronary artery calcification and its progression: what does it really mean? JACC Cardiovasc Imaging 2018;11:127-42. https://doi.org/10.1016/j. jcmg.2017.10.012; PMID: 29301708.

49. Vengrenyuk Y, Carlier S, Xanthos S, et al. A hypothesis for vulnerable plaque rupture due to stress-induced debonding around cellular microcalcifications in thin fibrous caps. Proc Natl Acad Sci U S A 2006:103:14678-83. https://doi. org/10.1073/pnas.0606310103; PMID: 17003118

50. Maldonado N, Kelly-Arnold A, Vengrenyuk Y, et al. A mechanistic analysis of the role of microcalcifications in atherosclerotic plaque stability: potential implications for plaque rupture. Am J Physiol Heart Circ Physiol 2012;303:H619-28. https://doi.org/10.1152/ ajpheart.00036.2012; PMID: 22777419

51. Kelly-Arnold A, Maldonado N, Laudier D, et al. Revised microcalcification hypothesis for fibrous cap rupture in human coronary arteries. Proc Natl Acad Sci U S A 2013;110:10741-6. https://doi.org/10.1073/pnas.1308814110; PMID: 23733926

52. Vengrenyuk Y, Cardoso L, Weinbaum S. Micro-CT based analysis of a new paradigm for vulnerable plaque rupture: Cellular microcalcifications in fibrous caps. Mol Cell Biomech 2008;5:37-47; PMID: 18524245.

53. Conroy RM, Pyörälä K, Fitzgerald AP, et al. Estimation of tenyear risk of fatal cardiovascular disease in Europe: the SCORE project. Eur Heart J 2003;24:987-1003. https://doi. org/10.1016/S0195-668X(03)00114-3; PMID: 12788299.

54. Goff DC, Jr., Lloyd-Jones DM, Bennett G, et al. 2013 ACC/ AHA guideline on the assessment of cardiovascular risk: a report of the American College of Cardiology/American Heart Association task force on practice guidelines. Circulation 2014;129:S49-73. https://doi.org/10.1161/01. cir.0000437741.48606.98; PMID: 24222018

55. Hobbs FD, Jukema JW, Da Silva PM, et al. Barriers to cardiovascular disease risk scoring and primary prevention in Europe. QJM 2010;103:727-39. https://doi.org/10.1093/ qjmed/hcq122; PMID: 20685842

56. Lauer MS. Primary prevention of atherosclerotic cardiovascular disease: the high public burden of low individual risk. JAMA 2007:297:1376-78, https://doi. org/10.1001/jama.297.12.1376; PMID: 17384436

57. Puchner SB, Liu T, Mayrhofer T, et al. High-risk plaque detected on coronary $\mathrm{CT}$ angiography predicts acute coronary syndromes independent of significant stenosis in acute chest pain: results from the ROMICAT-II trial. J Am Col Cardio/ 2014;64:684-92. https://doi.org/10.1016/j. jacc.2014.05.039; PMID: 25125300

58. Williams MC, Moss AJ, Dweck M, et al. Coronary artery plaque characteristics associated with adverse outcomes in the SCOT-HEART study. J Am Coll Cardiol 2019;73:291-301. https://doi.org/10.1016/j.jacc.2018.10.066; PMID: 30678759.

59. Motoyama S, Ito H, Sarai M, et al. Plaque characterization by coronary computed tomography angiography and the likelihood of acute coronary events in mid-term follow-up. J Am Coll Cardiol 2015;66:337-46. https://doi.org/10.1016/j. jacc.2015.05.069; PMID: 26205589

60. Ako J, Hibi K, Tsujita K, et al. Effect of alirocumab on coronary atheroma volume in Japanese patients with acute coronary syndrome - the ODYSSEY J-IVUS Trial. Circ $J$ 2019;83:2025-33. https://doi.org/10.1253/circj.CJ-19-0412; PMID: 31434809

61. Schuurman AS, Vroegindewey MM, Kardys I, et al. Prognostic value of intravascular ultrasound in patients with coronary artery disease. J Am Col Cardiol 2018;72:2003-11. https://doi.org/10.1016/j.jacc.2018.08.2140; PMID: 30336823

62. Stone GW, Maehara A, Lansky AJ, et al. A prospective natural-history study of coronary atherosclerosis $N$ Engl Med 2011;364:226-35.10.1056/NEJMoa1002358. https://do org/10.1056/NEJMoa1002358; PMID: 21247313

63. Calvert PA, Obaid DR, O'Sullivan M, et al. Association between IVUS findings and adverse outcomes in patients with coronary artery disease: the VIVA (VH-IVUS in
Vulnerable Atherosclerosis) study. JACC Cardiovasc Imaging 2011:4:894-901. https://doi.org/10.1016/j.jcmg.2011.05.005; PMID: 21835382

64. Räber L, Taniwaki M, Zaugg S, et al. Effect of high-intensity statin therapy on atherosclerosis in non-infarct-related coronary arteries (IBIS-4): a serial intravascular ultrasonography study. Eur Heart J 2015:36:490-500. https:// doi.org/10.1093/eurheartj/ehu373; PMID: 25182248 .

65. Räber L, Koskinas KC, Yamaji K, et al. Changes in coronary plaque composition in patients with acute myocardia infarction treated with high-intensity statin therapy (IBIS-4): a serial optical coherence tomography study. JACC CardiovasC Imaging 2019;12:1518-28. https://doi.org/10.1016/j. jcmg.2018.08.024; PMID: 30553686.

66. Kubo T, Ino Y, Mintz GS, et al. Optical coherence tomography detection of vulnerable plaques at high risk of developing acute coronary syndrome. Eur Heart J Cardiovasc Imaging 2021;22: 1376-84. https://doi.org/10.1093/ehjci/ jeab028; PMID: 33619524

67. Schuurman AS, Vroegindewey M, Kardys I, et al. Nearinfrared spectroscopy-derived lipid core burden index predicts adverse cardiovascular outcome in patients with coronary artery disease during long-term follow-up. Eur Heart J 2018;39:295-302. https://doi.org/10.1093/eurheartj/ ehx247; PMID: 28531282.

68. Erlinge D, Maehara A, Ben-Yehuda O, et al. Identification of vulnerable plaques and patients by intracoronary nearinfrared spectroscopy and ultrasound (PROSPECT III): a prospective natural history study. Lancet 2021;397:985-95. https://doi.org/101016/S0140-6736(21)00249-X. PMID: 33714389

69. Waksman R, Di Mario C, Torguson R, et al. Identification of patients and plaques vulnerable to future coronary events with near-infrared spectroscopy intravascular ultrasound imaging: a prospective, cohort study. Lancet 2019;394:1629 37. https://doi.org/10.1016/S0140-6736(19)31794-5; PMID: 31570255

70. Detrano R, Guerci AD, Carr JJ, et al. Coronary calcium as a predictor of coronary events in four racial or ethnic groups. N Engl J Med 2008;358:1336-45. https://doi.org/10.1056/ NEJMoa072100; PMID: 18367736.

71. Abdelrahman KM, Chen MY, Dey AK, et al. Coronary computed tomography angiography from clinical uses to emerging technologies: JACC state-of-the-art review. J Am Coll Cardiol 2020;76:1226-43. https://doi.org/10.1016/j. jacc.2020.06.076; PMID: 32883417

72. Cheng JM, Garcia-Garcia HM, de Boer SP, et al. In vivo detection of high-risk coronary plaques by radiofrequency intravascular ultrasound and cardiovascular outcome: results of the ATHEROREMO-IVUS study. Eur Heart J 2014;35:639-47. https://doi.org/10.1093/eurheartj/eht484; PMID: 24255128

73. Mintz GS, Nissen SE, Anderson WD, et al. American College Of Cardiology clinical expert consensus document on standards for acquisition, measurement and reporting of intravascular ultrasound studies (IVUS). A report of the American College of Cardiology task force on clinical expert consensus documents. J Am Coll Cardiol 2001;37:1478-92. https://doi.org/10.1016/s0735-1097(01)01175-5; PMID: 11300468

74. Fujii $\mathrm{K}, \mathrm{Hao} \mathrm{H}$, Ohyanagi M, et al. Intracoronary imaging for detecting vulnerable plaque. Circ J 2013;77:588-95. https:// doi.org/10.1253/circj.CJ-12-1599; PMID: 23370454.

75. Kume T, Akasaka T, Kawamoto T, et al. Measurement of the thickness of the fibrous cap by optical coherence tomography. Am Heart J 2006;152:755.e1-4. https://doi. org/10.1016/.ahj.2006.06.030; PMID: 16996853.

76. Narula J, Nakano M, Virmani R, et al. Histopathologic characteristics of atherosclerotic coronary disease and implications of the findings for the invasive and noninvasive detection of vulnerable plaques. J Am Coll Cardiol 2013;61:1041-51. https://doi.org/10.1016/j.jacc.2012.10.054 PMID: 23473409

77. Fujii K, Hao H, Shibuya M, et al. Accuracy of OCT, grayscale IVUS, and their combination for the diagnosis of coronary TCFA: an ex vivo validation study. JACC Cardiovasc Imaging 2015;8:451-60. https://doi.org/10.1016/j.jcmg.2014.10.015; PMID: 25797121

78. Tian J, Ren X, Vergallo R, et al. Distinct morphological features of ruptured culprit plaque for acute coronary events compared to those with silent rupture and thin-cap fibroatheroma: a combined optical coherence tomography and intravascular ultrasound study. J Am Coll Cardiol 2014;63:2209-16. https://doi.org/10.1016/j.jacc.2014.01.061; PMID: 24632266.

79. Tian J, Dauerman H, Toma C, et al. Prevalence and characteristics of tcfa and degree of coronary artery stenosis: an OCT, IVUS, and angiographic study. J Am Coll Cardiol 2014;64:672-80. https://doi.org/10.1016/i. jacc.2014.05.052; PMID: 25125298. 
80. Sinclair H, Bourantas C, Bagnall A, et al. OCT for the identification of vulnerable plaque in acute coronary syndrome. JACC Cardiovasc Imaging 2015;8:198-209.10.1016/ jcmg.2014.12.005. https://doi.org/10.1016/j.jcmg.2014.12.005; PMID: 25677892

81. Wang J, Geng YJ, Guo B, et al. Near-infrared spectroscopic characterization of human advanced atherosclerotic plaques. J Am Coll Cardio/ 2002;39:1305-13. https://doi. org/10.1016/S0735-1097(02)01767-9; PMID: 11955848.

82. Gardner CM, Tan H, Hull EL, et al. Detection of lipid core coronary plaques in autopsy specimens with a nove catheter-based near-infrared spectroscopy system. JACC Cardiovasc Imaging 2008;1:638-48. https://doi.org/10.1016/j. jcmg.2008.06.001; PMID: 19356494

83. Madder RD, Goldstein JA, Madden SP, et al. Detection by near-infrared spectroscopy of large lipid core plaques at culprit sites in patients with acute ST-segment elevation myocardial infarction. JACC Cardiovasc Interv 2013;6:838-46. https://doi.org/10.1016/j.jcin.2013.04.012; PMID: 23871513.

84. Choi BJ, Prasad A, Gulati R, et al. Coronary endothelia dysfunction in patients with early coronary artery disease is associated with the increase in intravascular lipid core plaque. Eur Heart J 2013;34:2047-54. https://doi.org/10.1093 eurheartj/eht132; PMID: 23569198.

85. Waxman S, Dixon SR, L'Allier $P$, et al. In vivo validation of a catheter-based near-infrared spectroscopy system for detection of lipid core coronary plaques: initial results of the SPECTACL study. JACC Cardiovasc Imaging 2009;2:858-68. https://doi.org/10.1016/i.jcmg.2009.05.001; PMID: 19608137.

86. Stone GW, Maehara A, Mintz GS. The reality of vulnerable plaque detection. JACC Cardiovasc Imaging 2011;4:902-4. https://doi.org/10.1016/j.jcmg.2011.06.006; PMID: 21835383.

87. Arbab-Zadeh A, Fuster V. The myth of the "vulnerable plaque": transitioning from a focus on individual lesions to atherosclerotic disease burden for coronary artery disease risk assessment. J Am Coll Cardiol 2015;65:846-55. https:// doi.org/10.1016/j.jacc.2014.11.041; PMID: 25601032.

88. Mann J, Davies MJ. Mechanisms of progression in native coronary artery disease: role of healed plaque disruption. Heart 1999;82:265-8. https://doi.org/10.1136/hrt.82.3.265. PMID: 10455072

89. Kubo T, Maehara A, Mintz GS, et al. The dynamic nature of coronary artery lesion morphology assessed by serial virtua histology intravascular ultrasound tissue characterization. J Am Coll Cardiol 2010;55:1590-7. https://doi.org/10.1016/j. jacc.2009.07.078; PMID: 20378076

90. Virmani R, Burke AP, Farb A, et al. Pathology of the vulnerable plaque. J Am Coll Cardiol 2006:47:c13-8. https:// doi.org/10.1016/j.jacc.2005.10.065; PMID: 16631505.

91. Naghavi M, Libby P, Falk E, et al. From vulnerable plaque to vulnerable patient: a call for new definitions and risk assessment strategies: part I. Circulation 2003;108:1664-72. https://doi.org/10.1161/01.CIR.0000087480.94275.97; PMID: 14530185

92. Naghavi M, Libby P, Falk E, et al. From vulnerable plaque to vulnerable patient: a call for new definitions and risk assessment strategies: part II. Circulation 2003;108:1772-8. https://doi.org/10.1161/01.CIR.0000087481.55887.C9. PMID: 14557340.

93. Davies MJ. The contribution of thrombosis to the clinical expression of coronary atherosclerosis. Thromb Res 1996:82:1-32. https://doi.org/10.1016/0049-3848(96)000357; PMID: 8731506

94. Arbab-Zadeh A, Nakano M, Virmani R, et al. Acute coronary events. Circulation 2012;125:1147-56. https://doi.org/10.1161/ CIRCULATIONAHA.111.047431; PMID: 22392862.

95. Baigent C, Keech A, Kearney PM, et al. Efficacy and safety of cholesterol-lowering treatment: prospective metaanalysis of data from 90,056 participants in 14 randomised trials of statins. Lancet 2005;366:1267-78. https://doi. org/10.1016/S0140-6736(05)67394-1; PMID: 16214597.

96. Arnett DK, Blumenthal RS, Albert MA, et al. 2019 ACC/AHA guideline on the primary prevention of cardiovascular disease: a report of the American College of Cardiology/ American Heart Association task force on clinical practice guidelines. J Am Coll Cardio/ 2019;74:e177-232. https://doi. org/10.1016/j.jacc. 2019.03.010; PMID: 30894318.

97. Mach F, Baigent C, Catapano AL, et al. 2019 ESC/EAS guidelines for the management of dyslipidaemias: lipid modification to reduce cardiovascular risk. Eur Heart J 2020;41:111-88. https://doi.org/10.1093/eurheartj/ehz455, PMID: 31504418.

98. Ray KK, Cannon CP. The potential relevance of the multiple lipid-independent (pleiotropic) effects of statins in the management of acute coronary syndromes. J Am Coll Cardiol 2005:46:1425-33. https://doi.org/10.1016/j. jacc.2005.05.086; PMID: 16226165.

99. Kataoka Y, Wolski K, Balog C, et al. Progression of coronary atherosclerosis in stable patients with ultrasonic features of high-risk plaques. Eur Heart J Cardiovasc Imaging 2014:15:1035-41. https://doi.org/101093/ehici/jeu065; PMID: 24780871

100. Lee SE, Chang HJ, Sung JM, et al. Effects of statins on coronary atherosclerotic plaques: the PARADIGM study. JACC Cardiovasc Imaging 2018;11:1475-84. https://doi. org/10.1016/j.jcmg.2018.04.015; PMID: 29909109

101. Ozaki Y, Garcia-Garcia HM, Beyene SS, et al. Effect of statin therapy on fibrous cap thickness in coronary plaque on optical coherence tomography - review and meta-analysis. Circ J 2019;83:1480-8. https://doi.org/10.1253/circj.CJ-181376; PMID: 31118354

102. Kataoka Y, Puri R, Hammadah M, et al. Frequency-domain optical coherence tomographic analysis of plaque microstructures at nonculprit narrowings in patients receiving potent statin therapy. Am J Cardiol 2014:114:549 54. https://doi.org/10.1016/j.amjcard.2014.05.035; PMID: 24996554

103. Giugliano RP, Sabatine MS. Are PCSK9 inhibitors the next breakthrough in the cardiovascular field? J Am Coll Cardiol 2015;65:2638-51. https://doi.org/10.1016/j.jacc.2015.05.001; PMID: 26088304

104. Robinson JG, Farnier M, Krempf M, et al. Efficacy and safety of alirocumab in reducing lipids and cardiovascular events. N Engl J Med 2015;372:1489-99. https://doi.org/10.1056/ NEJMoa1501031; PMID: 25773378.

105. Sabatine MS, Giugliano RP, Keech AC, et al. Evolocumab and clinical outcomes in patients with cardiovascular disease. N Engl J Med 2017;376:1713-22. https://do. org/101056/NEJMoa1615664: PMID: 28304224.

106. Grundy SM, Stone NJ, Bailey AL, et al. 2018 AHA/ACC AACVPR/AAPA/ABC/ACPM/ADA/AGS/APHA/ASPC/NLA/PCNA guideline on the management of blood cholesterol: a report of the American College of Cardiology/American Heart Association task force on clinical practice guidelines. Circulation 2019;139:e1082-143. https://doi.org/10.1161/ CIR.0000000000000698; PMID: 30586774.

107. Nicholls SJ, Puri R, Anderson T, et al. Effect of evolocumab on coronary plaque composition. J Am Coll Cardiol 2018;72:2012-21. https://doi.org/10.1016/j.jacc.2018.06.078, PMID: 30336824

108. Zanchin C, Koskinas KC, Ueki Y, et al. Effects of the PCSK9 antibody alirocumab on coronary atherosclerosis in patients with acute myocardial infarction: a serial, multivessel, intravascular ultrasound, near-infrared spectroscopy and optical coherence tomography imaging study - rationale and design of the PACMAN-AMI trial. Am Heart J 2021:238:33-44. https://doi.org/10.1016/..ahj.2021.04.006: PMID: 33951415.

109. Ridker PM, Cushman M, Stampfer MJ, et al. Inflammation, aspirin, and the risk of cardiovascular disease in apparently healthy men. N Engl J Med 1997;336:973-9. https://doi. org/10.1056/NEJM199704033361401; PMID: 9077376.

110. Ridker PM, Everett BM, Thuren T, et al. Antiinflammatory therapy with canakinumab for atherosclerotic disease. N Engl J Med 2017;377:1119-31. https://doi.org/10.1056/ NEJMoa1707914: PMID: 2884575

111. Ridker PM, Everett BM, Pradhan A, et al. Low-dose methotrexate for the prevention of atherosclerotic events. N Engl J Med 2019;380:752-62. https://doi.org/10.1056/ NEJMoa1809798; PMID: 30415610.
112. Slobodnick A, Shah B, Krasnokutsky S, et al. Update on colchicine, 2017. Rheumatology (Oxford) 2018:57(Suppl i):i4-11. https://doi.org/10.1093/rheumatology/kex453; PMID: 29272515

113. Nidorf SM, Eikelboom JW, Budgeon CA, et al. Low-dose colchicine for secondary prevention of cardiovascular disease. J Am Coll Cardiol 2013;61:404-10. https://doi. org/10.1016/j.jacc.2012.10.027; PMID: 23265346.

114. Nidorf SM, Fiolet ATL, Mosterd A, et al. Colchicine in patients with chronic coronary disease. N Engl J Med 2020;383:1838-47. https://doi.org/10.1056/NEJMoa2021372; PMID: 32865380

115. Tardif JC, Kouz S, Waters DD, et al. Efficacy and safety of low-dose colchicine after myocardial infarction. N Engl J Med 2019;381:2497-505. https://doi.org/10.1056/NEJMoa1912388; PMID: 31733140

116. Maron DJ, Hochman JS, Reynolds HR, et al. Initial invasive or conservative strategy for stable coronary disease. N Engl J Med 2020;382:1395-407. https://doi.org/10.1056 NEJMoa1915922; PMID: 32227755

117. Chacko L, Howard JP, Rajkumar $C$, et al. Effects of percutaneous coronary intervention on death and myocardial infarction stratified by stable and unstable coronary artery disease: a meta-analysis of randomized controlled trials. Circ Cardiovasc Qual Outcomes 2020;13:e006363. https://doi.org/10.1161/ CIRCOUTCOMES.119.006363; PMID: 32063040

118. Stone GW, Maehara A, Muller JE, et al. Plaque characterization to inform the prediction and prevention of periprocedural myocardial infarction during percutaneous coronary intervention: the CANARY trial (Coronary Assessment by Near-infrared of Atherosclerotic Ruptureprone Yellow). JACC Cardiovasc Interv 2015;8:927-36. https:// doi.org/10.1016/j.jcin.2015.01.032; PMID: 26003018.

119. Kramer MC, Rittersma SZ, de Winter RJ, et al. Relationship of thrombus healing to underlying plaque morphology in sudden coronary death. J Am Coll Cardiol 2010;55:122-32. https://doi.org/10.1016/j.jacc.2009.09.007; PMID: 19818571.

20. Serruys PW, Garcia-Garcia HM, Onuma Y. From metallic cages to transient bioresorbable scaffolds: change in paradigm of coronary revascularization in the upcoming decade? Eur Heart J 2012;33:16-25. https://doi.org/10.1093/ eurhearti/ehr384; PMID: 22041548.

121. Nakazawa G, Otsuka F, Nakano M, et al. The pathology of neoatherosclerosis in human coronary implants bare-meta and drug-eluting stents. J Am Coll Cardiol 2011;57:1314-22. https://doi.org/10.1016/S0735-1097(11)62051-2; PMID: 21376502

122. Hu S, Zhu Y, Zhang Y, et al. Management and outcome of patients with acute coronary syndrome caused by plaque rupture versus plaque erosion: an intravascular optical coherence tomography study. J Am Heart Assoc 2017;6. https://doi.org/101161/JAHA.116.004730. PMID: 282335809.

123. He L, Qin Y, Xu Y, et al. Predictors of non-stenting strategy for acute coronary syndrome caused by plaque erosion: four-year outcomes of the EROSION study. Eurolntervention 2021;17:497-505. https://doi.org/10.4244/EIJ-D-20-00299; PMID: 33164894

124. Koskinas KC, Nakamura M, Räber L, et al. Current use of intracoronary imaging in interventional practice - results of a European Association of Percutaneous Cardiovascular Interventions (EAPCI) and Japanese Association of Cardiovascular Interventions and Therapeutics (CVIT) clinica practice survey. Eurolntervention 2018;14:e475-84. https://doi. org/10.4244/EIJY18M03_01; PMID: 29537966.

125. Alberti A, Giudice P, Gelera A, et al. Understanding the economic impact of intravascular ultrasound (IVUS). Eur J Health Econ 2016;17:185-93. https://doi.org/10.1007/s10198 015-0670-4; PMID: 25669755

26. Maehara A, Mintz GS, Witzenbichler B, et al. Relationship between intravascular ultrasound guidance and clinical outcomes after drug-eluting stents. Circ Cardiovasc Inter 2018;11:e006243. https://doi.org/10.1161/ CIRCINTERVENTIONS.117.006243; PMID: 30571206 